\title{
Implementation of Software-Efficient DES Algorithm
}

\author{
Mohammad Taghipour ${ }^{1, *}$, Arash Moghadami , Behbood Moghadam Naghdi Shekardasht ${ }^{2}$ \\ ${ }^{1}$ Industrial Engineering, Science \& Research Branch of Islamic Azad University, Tehran, Iran \\ ${ }^{2}$ Electrical Engineering, Telecommunications, Non-Profit Institute of Higher Education, Aba - Abyek Qazvin, Iran \\ Email address: \\ Mohamad.taghipour@srbiau.ac.ir(M. Taghipour),moghadami.arash@yahoo.com (A. Moghadami), \\ behboodmoghadam@gmail.com (B. M. N. Shekardasht)
}

\section{To cite this article:}

Mohammad Taghipour, Arash Moghadami, Behbood Moghadam Naghdi Shekardasht. Implementation of Software-Efficient DES Algorithm. Advances in Networks. Special Issue: Secure Networks and Communications. Vol. 3, No. 3-1, 2015, pp. 7-22.

doi: 10.11648/j.net.s.2015030301.12

\begin{abstract}
By increasing development of digital telecommunication and the increase of sending and receiving data of various network of data transfer, protection of the safety of data are the most important necessities of the current world. The increase of different bank trading, increasing use of smart cards, moving to electronic government, are the examples of significance of this issue. DES algorithm is introduced by IBM company and is applied for many years by technology and standard institute of US as data encryption standard algorithm and it is also applied in many applications as networks as ATM and smart cards. Software-efficient implementation of this algorithm is one of the important research issues for engineers working in this field as we can perform rapidly on smart cards. In this study, an efficient algorithm implementation by MATLAB and C language is presented and is compared with the latest works in this field.
\end{abstract}

Keywords: Digital Telecommunication, Cryptography, Decryption, Safe Communication, DES Algorithm

\section{Introduction}

The development of internet has made great changes in the life style and job activity of people, organizations and institutes. The data security is one of the common issues of legal and real entities. Assurance of the lack of access of unauthorized users to sensitive data are the most important challenges regarding data distribution in internet. Sensitive information as hidden from other people includes various items and some of them are:

- Credit card information

- Membership numbers in associations

- Private information

- Details of personal information

- Sensitive information in an organization

- Information of bank accounts

There are not complexities of human relations as mutual trust in electronic relations and a science should prepare the conditions and these relations should be guaranteed. Thus, cryptography is the knowledge of guaranteeing the relations as without cryptography, there is no guarantee in digital communication world. Cryptography is the knowledge dealing with the principles of transfer or storage of information as secure, even if the transfer path and communication channels or data storage is insecure. Cryptography has been used to protect information, consistency of sent and received data, authentication of identity and these principles should be observed in each type of cryptography. Protecting information and confidentiality means that only the sender and receiver understands the content of message and it is possible other people can see its content but its content should be ambiguous from their view.

In the mid 70s, DES algorithm as FIPS - PUB - 46 is applied as data encryption standard and various institutes as NIST, IEEE, etc. consider it as an algorithm with suitable security for the applications without classification. Since then, hardware and software algorithm implementation is investigated on various grounds as microcontrollers, smart cards, FPGAs, etc. in various papers. For example, we can refer to the followings:

FIPS - PUB - 46-1

FIPS - PUB $-46-2$

FIPS - PUB $-46-3$

FIPS - PUB - 197

The purpose of this study besides recognition of function of data encryption algorithm and its simulation in MATLAB is presenting an efficient implementation of algorithm and improvement of implementation performance in comparison 
with others works.

Study hypotheses are as followings:

- The structure of algorithm and its key length are defined.

- The implementation is $\mathrm{PC}$ and implementation language is MATLAB and C.

- Having common calculation ability

- Initial recognition of architectures and methods of algorithm implementation of reported previous works

- Theoretical basics

\section{Cryptography}

With the advent of computer and increasing their calculation ability, cryptography entered computer sciences and this caused three major changes in cryptography:

- High calculation power allowed the possibility that complex and effective methods are created for cryptography.

- The cryptography methods that were used for Ciphering the message had various and new applications.

- Before that, cryptography was mostly on text data and alphabets but after computer, cryptography was performed on different data and based on bit.

\subsection{The History and Structure of DES Algorithm}

DES algorithm was raised in 70 s in US as a coding standard. This algorithm accepts a series of main text with constant length as input and after doing complex works on its, output is produced with the length equal to input length. A key is used for encryption and only those who know the key value can decode it. Although some analyses are made about DES more than any other block encryption method, the most practical attack against this algorithm is comprehensive search of key space. There are three theoretical attacks for this algorithm as needing less time compared to comprehensive searching of key space but these methods are not possible.

\subsection{DES Encryption}

Data encryption standard (DES) is a math algorithm applied for cryptography and Decryption of coded binary data. Cryptography converts data to Cipher. Decryption of cipher, returns to the main data. The mentioned algorithm defines both cryptography and Decryption based on binary value as key. The data are recovered by cipher, if the same key is used for Decryption as it was used for encryption. DES algorithm is composed of two:

DES cryptography algorithm

DES algorithm includes some repetitions of a plain transformation by substitution and transposition techniques. This algorithm only applies one key for encryption and decryption and it is called private key encryption. Thus, keeping the key as confidential by sender and transmitter is of great importance as the algorithm is public and in case of revealing key, any person can see the confidential message.
Thus, in DES cryptography, the life of key is as long as the life of transaction.

DES cryptography key

DES key is an 8-bit sequence and each bit includes a7-bit key and a parity bit. During cryptography, DES algorithm breaks the main text into 64-bit blocks. This algorithm works on a block and it is broken into half and encryption is done character to character. Characters are permuted 16 times under the key supervision and finally an encrypted 64-bit text is produced. The key with 56 bit is useful and 8-bit is for parity.

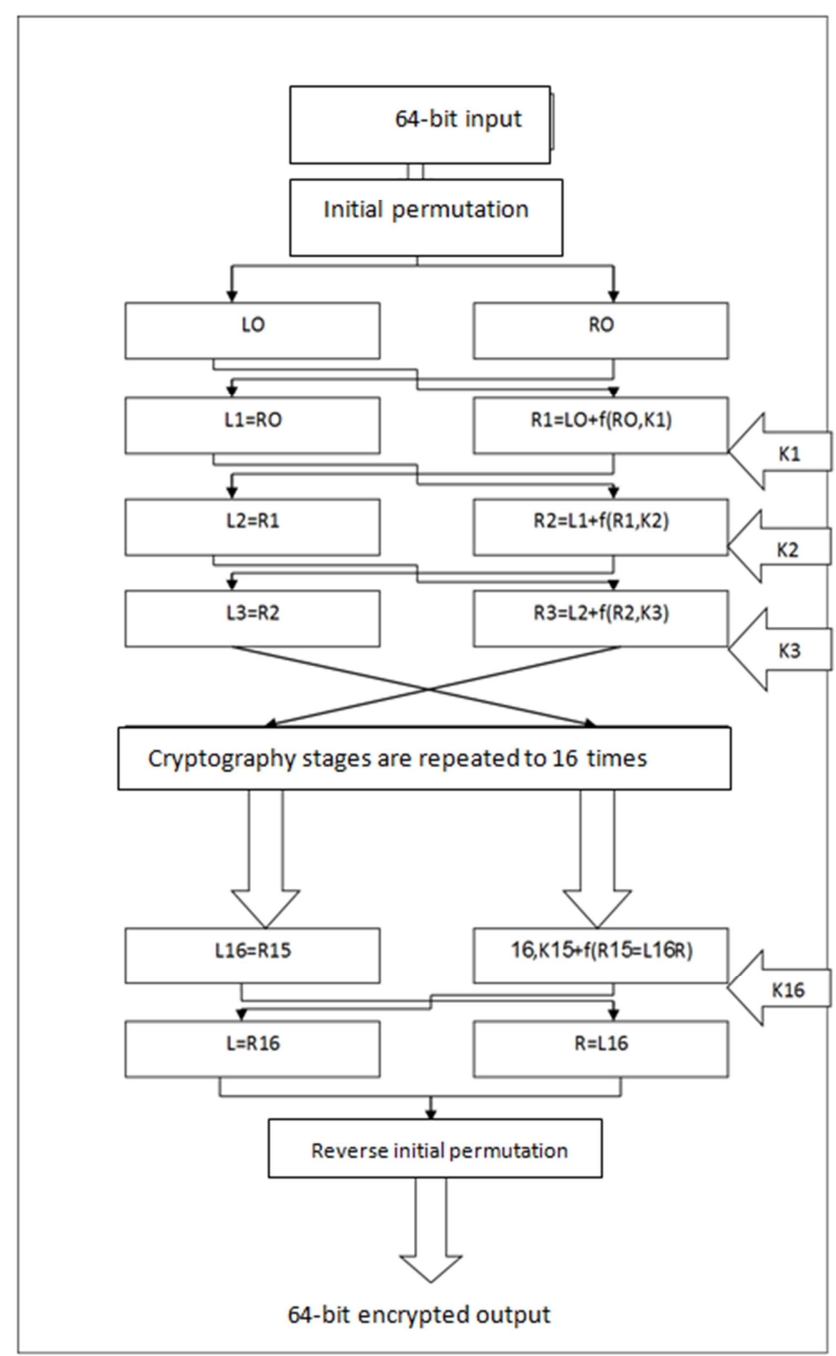

Figure 2-1. Algorithm of DES cryptography method DES algorithm structure.

In DES, the length of blocks is 64 bit. The key consists of 64 bit but only 56 bits are used and other 8 bits are only used to check parity. The algorithm includes 16 simialr rounds and each stage is called a round. The text being encrypted is at first subject to initial permutation (IP). Then, a series of complex acts on done on the key and finally it is subject to final permutation (FP). IP and FP are inverses. FP undoes the action of IP. IP and FP have no cryptographic significance, but were included in order to facilitate loading blocks in mid1970s 8-bit based hardware but DES was performed slow in 
software [5]. Before the main round, the block is divided into two 32-bit halves and processed alternately; this crisscrossing is known as the Feistel scheme. The Feistel structure ensures that decryption and encryption are very similar processes, the only difference is that the subkeys are applied in the reverse order when decrypting. The rest of the algorithm is identical. This greatly facilitates implementation, particularly in hardware, as there is no need for different encryption and decryption algorithms.

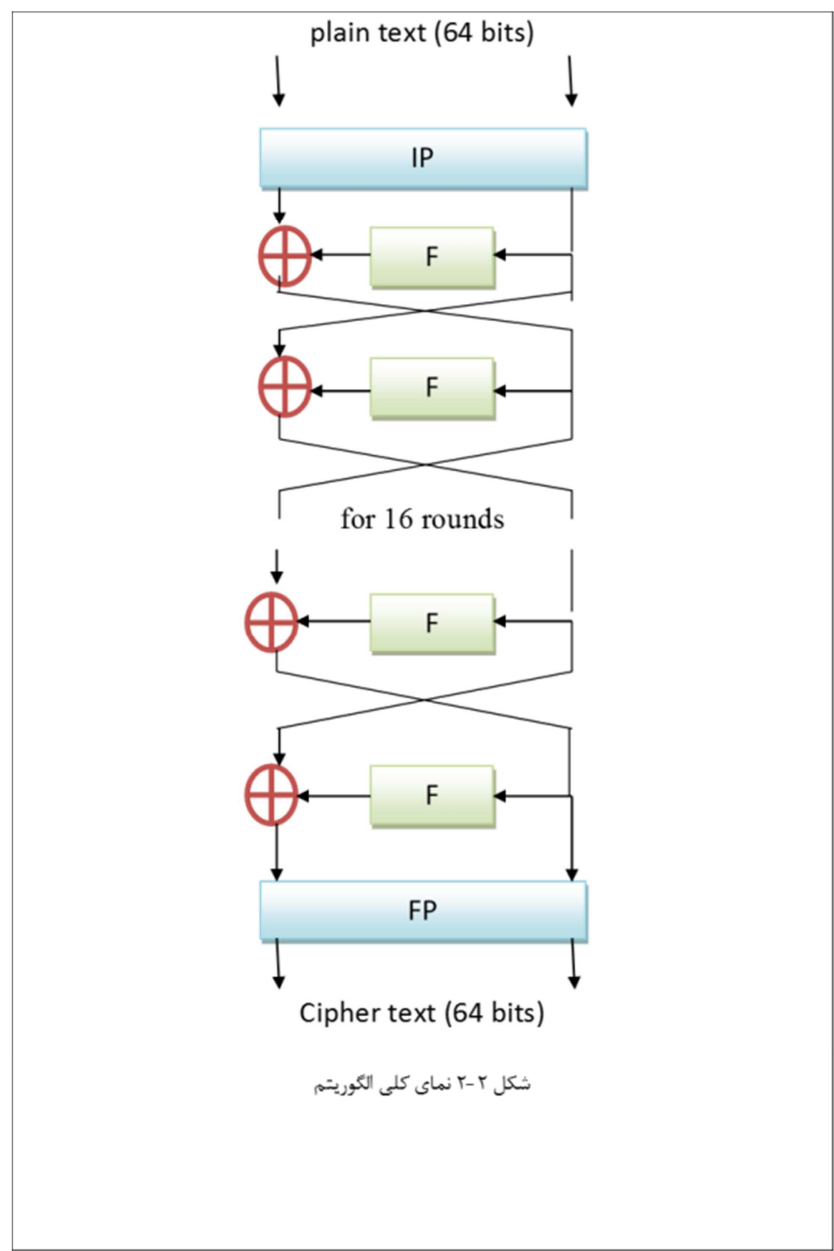

Figure 2-2. General view of algorithm.

The function including IP output and providing FP after 16 input rounds is called function $\mathrm{F}$. This function has a 32-bit input and a 48-bit input and a 32-bit output. The entrance block is consists of 32 bits and left half and is denoted by $\mathrm{L}$ and other 32 bits as right half are denoted by $\mathrm{R}$ and the entire block is denoted by LR.

If $\mathrm{K}$ is a 48-bit block derived of main 64-bit key and output of a round with input LR and output L1R1 are defined as $\mathrm{L} 1=\mathrm{R} \mathrm{R} 1=\mathrm{L}$ XOR $\mathrm{F}(\mathrm{R}, \mathrm{K})$. If $\mathrm{KS}$ is a function with 64-bit key and an integer ranging 1-16 as input, 48-bit key of $\mathrm{KN}$ generates an output as KN bits are obtained by KEY bits and we have $\mathrm{KN}=\mathrm{KS}$ (N.KEY):

$\mathrm{KS}$ is called Key schedule function. Thus, we have:

$\mathrm{LN}=\mathrm{Rn}-1 \mathrm{RN}=\mathrm{Ln}-1$ XOR $\mathrm{f}(\mathrm{Rn}-1, \mathrm{KN})$

For decryption we have: $\mathrm{R}=\mathrm{L} 1 \mathrm{~L}=\mathrm{R} 1 \mathrm{XOR} \mathrm{f}(\mathrm{L} 1, \mathrm{~K})$. Thus, decryption is done with the same algorithm as applied for decryption and in each stage, the same k-bit is used as key for decryption and we can say:

\section{$\mathrm{RN}-1=\mathrm{LN} \mathrm{LN}-1=\mathrm{RN}$ XOR $\mathrm{f}(\mathrm{LN}, \mathrm{KN})$}

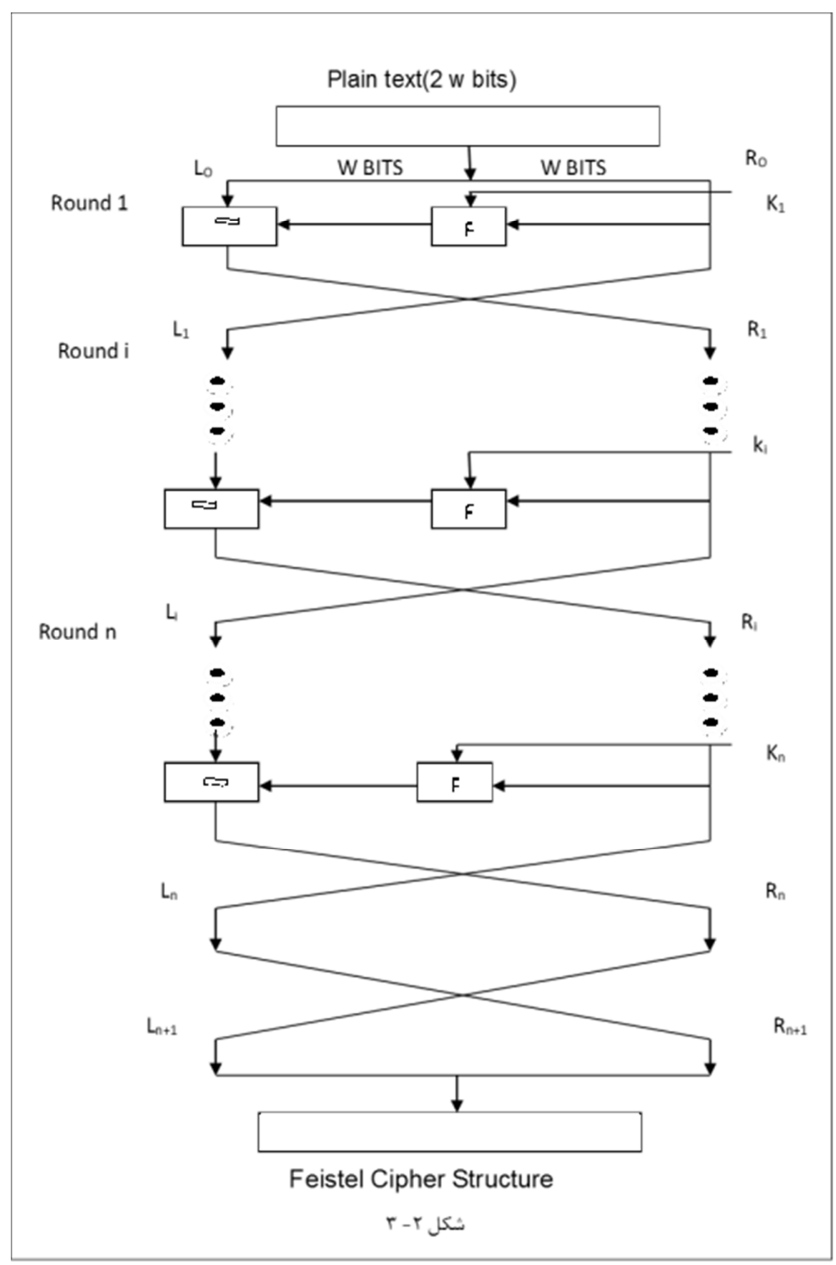

Figure 3-2. Feistel Cipher Structure

To compute decryption R16L16 is input of and R0L0 is input of FP. The $16^{\text {th }}$ key in the first round, $15^{\text {th }}$ key in the second round and the first key in $16^{\text {th }}$ round can be used [3].

\section{Simulation and Implementation of DES Algorithm}

\subsection{Step by Step DES Code}

In this algorithm a 64-bit block is received from data (plaintext) and then a coded 64-bit block is delivered (cipher text).

This algorithm is composed of 16 rounds, the main algorithm is coded to generate data and is repeated 16 times.

An important point regarding the above key: in DES algorithm, the coefficients of $8^{\text {th }}$ bit of key are not used, it means that bits $8,16,24,32,40,48,56,64$ are not considered (thus, effective length is 56-bit key).

Now, DES algorithm starts:

First stage 
Creating 16 subkeys, each with the length of 48bits

At first, it is required to be familiar with Permuted choice 1 as PC-1:

PC-1

5749413325179

1585042342618

1025951433527

1911360524436

63554739312315

7625446383022

1466153453729

211352820124

Since the first entry in the table is 57 , this means that the 57 th bit of the original key $\mathrm{K}$ becomes the first bit of the permuted key $(\mathrm{K}+)$. The 49th bit of the original key becomes the second bit of the permuted key and this continues. Thus, based on the above values, we have:

$\mathrm{K}=0001001100110100010101110111100110011011$ 1011110011011111

\section{1}

$\mathrm{K}--->(\mathrm{PC}-1)--->\mathrm{K}+$

$\mathrm{K}+=1111000 \quad 0110011 \quad 0010101 \quad 01011110101010$ 101100110011110001111

\section{Second stage}

Then $\mathrm{K}+$ is divided into two 28-bit halves:

$\mathrm{C} 0=1111000011001100101010101111$

D0 $=0101010101100110011110001111$

As shown, in this stage, 16 sub-keys are created (Cn,Dn) ( $\mathrm{n}$ is ranging 1-16). These 16 subkeys are generated of D0, $\mathrm{C} 0$ as followings.

At first, consider the following Table:

\begin{tabular}{ll}
\hline Iteration Number & Number of Rotate left shift \\
\hline 1 & 1 \\
2 & 1 \\
3 & 2 \\
4 & 2 \\
5 & 2 \\
6 & 2 \\
7 & 2 \\
8 & 2 \\
9 & 1 \\
10 & 2 \\
11 & 2 \\
12 & 2 \\
13 & 2 \\
14 & 2 \\
15 & 2 \\
16 & 1 \\
\hline
\end{tabular}

Recalling:

1111000011001100101010101111 (1 Rotate left shift) 1110000110011001010101011111

Based on C0, D0 and above shifts Table, we have:

$\mathrm{C} 0=1111000011001100101010101111$

D0 $=0101010101100110011110001111$

$\mathrm{C} 1=1110000110011001010101011111$

$\mathrm{D} 1=1010101011001100111100011110$

$\mathrm{C} 2=1100001100110010101010111111$

D2 $=0101010110011001111000111101$

$\mathrm{C} 3=0000110011001010101011111111$
D3 $=0101011001100111100011110101$

$\mathrm{C} 4=0011001100101010101111111100$

D4 $=0101100110011110001111010101$

C $5=1100110010101010111111110000$

D5 $=0110011001111000111101010101$

C6 $=0011001010101011111111000011$

D6 $=1001100111100011110101010101$

$\mathrm{C} 7=1100101010101111111100001100$

D7 $=0110011110001111010101010110$

$\mathrm{C} 8=0010101010111111110000110011$

$\mathrm{D} 8=1001111000111101010101011001$

C9 $=0101010101111111100001100110$

D9 $=0011110001111010101010110011$

$\mathrm{C} 10=0101010111111110000110011001$

$\mathrm{D} 10=1111000111101010101011001100$

$\mathrm{C} 11=0101011111111000011001100101$

$\mathrm{D} 11=1100011110101010101100110011$

$\mathrm{C} 12=0101111111100001100110010101$

$\mathrm{D} 12=0001111010101010110011001111$

$\mathrm{C} 13=0111111110000110011001010101$

$\mathrm{D} 13=0111101010101011001100111100$

$\mathrm{C} 14=1111111000011001100101010101$

D14 $=1110101010101100110011110001$

$\mathrm{C} 15=1111100001100110010101010111$

$\mathrm{D} 15=1010101010110011001111000111$

$\mathrm{C} 16=1111000011001100101010101111$

D16 $=0101010101100110011110001111$

Now, we apply PC-2 on above pairs to create Kn. This permutation Table 2 is as followings:

PC-2

1417112415

3281562110

2319124268

1672720132

415231374755

304051453348

444939563453

464250362932

Based on the above calculations we have:

$\mathrm{C} 1 \mathrm{D} 1=11100001100110010101010111111010101$ 011001100111100011110

Now, PC-2 should be applied independently on one by one of 16 sub-keys, for example in $\mathrm{K} 1$ (as shown in the above Table), the first bit is equal to the $14^{\text {th }} \mathrm{C} 1 \mathrm{D} 1 \mathrm{bit}$, the second bit $\mathrm{K} 1$ equal to the $17^{\text {th }} \mathrm{C} 1 \mathrm{D} 1$ bit and so on.

Finally, after applying PC-2 on calculated CnDn, we have:

$\mathrm{K} 1=000110110000001011 \quad 101111 \quad 111111000111$ 000001110010

$\mathrm{K} 2=011110 \quad 011010 \quad 111011011001 \quad 110110111100$ 100111100101

$\mathrm{K} 3=010101011111110010001010010000101100$ 111110011001

$\mathrm{K} 4=011100101010110111010110110110110011$ 010100011101

$\mathrm{K} 5=011111001110110000000111 \quad 111010110101$ 001110101000

$\mathrm{K} 6=011000111010010100111110010100000111$ 


\section{1}

$\mathrm{K} 7=111011001000010010110111111101100001$

100010111100

$\mathrm{K} 8=111101 \quad 111000101000111010110000010011$

101111111011

$\mathrm{K} 9=111000001101101111101011111011011110$

011110000001

$\mathrm{K} 10=101100011111001101000111101110100100$

011001001111

$\mathrm{K} 11=001000010101111111010011110111101101$

001110000110

$\mathrm{K} 12=011101010111000111110101100101000110$

01111101001

$\mathrm{K} 13=100101111100010111010001111110101011$

101001000001

$\mathrm{K} 14=010111110100001110110111111100101110$

011100111010

$\mathrm{K} 15=101111111001000110001101001111010011$

111100001010

$\mathrm{K} 16=110010110011110110001011000011100001$

011111110101

Third stage

If we summarize Subkey, we have

$\mathrm{C}[0] \mathrm{D}[0]=\mathrm{PC} 1$ (key)

for $1<=\mathrm{i}<=16$

$\mathrm{C}[\mathrm{i}]=\mathrm{LS}[\mathrm{i}](\mathrm{C}[\mathrm{i}-1])$

$\mathrm{D}[\mathrm{i}]=\mathrm{LS}[\mathrm{i}](\mathrm{D}[\mathrm{i}-1])$

$\mathrm{K}[\mathrm{i}]=\mathrm{PC} 2(\mathrm{C}[\mathrm{i}] \mathrm{D}[\mathrm{i}])$

Then, we start the coding of 64-bit blocks (DES Core

Function). Consider the following Table:

IP

585042342618102

605244362820124

625446383022146

645648403224168

57494133251791

595143352719113

615345372921135

635547393123157

IP table here means initial permutation and is applied on initial message, $\mathrm{M}$.

$\mathrm{M}=000000010010001101000101011001111000$ 1001101010111100110111101111

IP = 1100110000000000110011001111111111110000 101010101111000010101010

Like the apply methods of previous tables, $58^{\text {th }}$ bit of $\mathrm{M}$ here as " 1 " is the first IP bit, then $50^{\text {th }}$ bit of $M$ here is " 1 " and it is the second IP bit and so on. Then, IP is divided into two 32-bit left and right halves:

L0 = 11001100000000001100110011111111

$\mathrm{R} 0=11110000101010101111000010101010$

The general formula of this 16 rounds is as followings:

$\mathrm{L}[\mathrm{n}]=\mathrm{R}[\mathrm{n}-1]$

$\mathrm{R}[\mathrm{n}]=\mathrm{L}[\mathrm{n}-1]$ XOR $\mathrm{f}(\mathrm{R}[\mathrm{n}-1], \mathrm{K}[\mathrm{n}])$

Here, $\mathrm{n}$ is ranging 1,16 rounds. Regarding f function, we explain later.

For example, for $\mathrm{N}=1$, we have:

The items calculated are as:
$\mathrm{L}[0]=11001100000000001100110011111111$

$\mathrm{R}[0]=11110000101010101111000010101010$

$\mathrm{K}[1]=000110110000001011101111111111000111$ 000001110010

Then,

$\mathrm{L}[1]=\mathrm{R}[0]=11110000101010101111000010101010$

$\mathrm{R}[1]=\mathrm{L}[0]+\mathrm{f}(\mathrm{R}[0], \mathrm{K}[1])$

The rest is regarding explanation of $\mathrm{f}$ function performance in above equation:

To compute f, at first 32-bit $\mathrm{R}[\mathrm{n}-1]$ should be extended to 48bit. To do this, selection table as $\mathrm{E}$ is used: $\mathrm{E}(\mathrm{R}[\mathrm{n}-1])$

The above function has input bit with 48-bit output. The table is as:

E BIT-SELECTION TABLE

3212345

456789

8910111213

121314151617

161718192021

202122232425

242526272829

28293031321

Calculation of function $\mathrm{f}$ continues...

Fourth stage

In the continuance of previous section, we calculate $\mathrm{E}(\mathrm{R}$ [0]) from $R[0]$ :

$R[0]=11110000101010101111000010101010$

$\mathrm{E}(\mathrm{R}[0])=011110100001010101010101011110100001$ 010101010101

As shown, by apply of Table E, each four initial bits are extended to 6 bits.

In the continuance of calculation of output $f E(R[n-1])$ with key $\mathrm{K}[\mathrm{n}]$ is XOR. for example,

$\mathrm{K}[1]=000110110000001011101111111111000111$ 000001110010

$\mathrm{E}(\mathrm{R}[0])=011110100001010101010101011110100001$ 010101010101

$\mathrm{K} 1 \mathrm{XOR} \mathrm{E}(\mathrm{R}[0])=011000010001011110111010$ 100001100110010100100111

Calculation of $\mathrm{f}$ is not completed yet. Here, $\mathrm{E}(\mathrm{R}[\mathrm{n}])$ is extended from 32 bit to 48 bit by Table E. Then the result with $\mathrm{K}[\mathrm{n}]$ is XOR. Now 48bit or eight 6-bit group is the result. We attribute some names as $\mathrm{B}[1]$ to $\mathrm{B}[8]$ to these 8 groups. It means that:

$\mathrm{K}[\mathrm{n}]$ XOR $\mathrm{E}(\mathrm{R}[\mathrm{n}]-1)=\mathrm{B}[1] \mathrm{B}[2] \mathrm{B}[3] \mathrm{B}[4] \mathrm{B}[5] \mathrm{B}[6]$ $\mathrm{B}[7] \mathrm{B}[8]$

Later we refer to another operation on $\mathrm{B}[\mathrm{i}]$. Here another concept as SBoxes is presented. These Tables should be applied on $\mathrm{B}[\mathrm{i}]$. It means that:

$\mathrm{S} 1(\mathrm{~B}[1]) \mathrm{S} 2(\mathrm{~B}[2]) \mathrm{S} 3(\mathrm{~B}[3]) \mathrm{S} 4(\mathrm{~B}[4]) \mathrm{S} 5(\mathrm{~B}[5]) \mathrm{S} 6(\mathrm{~B}[6])$ $\mathrm{S} 7(\mathrm{~B}[7]) \mathrm{S} 8(\mathrm{~B}[8])$

The Tables are as:

S1

1441312151183106125907

0157414213110612119538

4114813621115129731050

1512824917511314100613

S2 
1518146113497213120510

3134715281412011069115

0147111041315812693215

1381013154211671205149

S3

1009146315511312711428

1370934610285141211151

1364981530111212510147

1101306987415143115212 S4

7131430691012851112415

1381156150347212110149

1069012117131513145284

3150610113894511127214

S5

2124171011685315130149

1411212471315015103986

4211110137815912563014

1181271142136150910453

S6

1211015926801334147511

1015427129561131401138

9141552812370410113116

4321295151011141760813

S7

4112141508133129751061

1301174911014351221586

1411131237141015680592

6111381410795015142312

S8

1328461511110931450127

1151381037412561101492

7114191214206101315358

2114741081315129035611

The applying method of $\mathrm{S}$ Boxes as different from other

Tables as evaluated in the next section.

Fifth stage

The application method of S-boxes or Substitution boxes

Let we have 48-bit binary value and we want to apply S-

boxes on it:

011101000101110101000111101000011100101101011101

As it was said, eight 6-bit groups are extracted from it composed of B1 to B8 as:

$\begin{array}{lllllll}011101 & 000101 & 110101 & 000111 & 101000 & 011100 & 101101\end{array}$ 011101

The following calculations are considered:

$\mathrm{B}[\mathrm{n}]=>\mathrm{S}[\mathrm{n}][$ row $][$ column $]$

$\mathrm{B}[1]=>\mathrm{S}[1](01,1110)=\mathrm{S}[1][1][14]=3=0011$

$\mathrm{B}[2]=>\mathrm{S}[2](01,0010)=\mathrm{S}[2][1][2]=4=0100$

$\mathrm{B}[3]=>\mathrm{S}[3](11,1010)=\mathrm{S}[3][3][10]=14=1110$

$\mathrm{B}[4]=>\mathrm{S}[4](01,0011)=\mathrm{S}[4][1][3]=5=0101$

$\mathrm{B}[5]=>\mathrm{S}[5](10,0100)=\mathrm{S}[5][2][4]=10=1010$

$\mathrm{B}[6]=>\mathrm{S}[6](00,1110)=\mathrm{S}[6][0][14]=5=0101$

$\mathrm{B}[7]=>\mathrm{S}[7](11,0110)=\mathrm{S}[7][3][6]=10=1010$

$\mathrm{B}[8]=>\mathrm{S}[8](01,1110)=\mathrm{S}[8][1][14]=9=1001$

Calculation method:

$\mathrm{B}[\mathrm{n}]=>\mathrm{S}[\mathrm{n}][$ row $][$ column $]$ $\mathrm{n}$ : Is equal to $\mathrm{B}$ index

Row: It is created of putting the first and final bit of a 6-bit group.

Column: The rest of bits creates column (from bits 2-5)

For example:

Consider 011101

As the first 6-bit group is our 48-bit value, $\mathrm{n}=1$.

To create row, two first and final bits are together, ROW $=01$

The column is composed of bit 2 to 5 , Column $=1110$

Result:

The first calculation as mentioned in the above:

$\mathrm{S}[\mathrm{n}][$ row $][$ column $]=\mathrm{S}[1](01,1110)$

To compute this situation in Table S1, at first the values in parenthesis are converted into their decimal equivalent and we have:

$\mathrm{S}[1][1][14]$

$\mathrm{S} 1$ Table is as followings (For easy reference, the Number of rows and columns is written, 0-3 as number of rows and 015 as the number of columns (Blue) :

S1 (ROW/Column)

0123456789101112131415

01441312151183106125907

10157414213110612119538

24114813621115129731050

31512824917511314100613

Then, this situation is found in Table S1. We refer to S1 Table and we find the value in row 1 and column. This value is equal to 3 and then it is converted to binary value. Thus, we have:

$\mathrm{B}[1]=\mathrm{S}[1](01,1110)=\mathrm{S}[1][1][14]=3=0011$

Then, it is applied for other 6-bit groups.

The result is putting together the above results as a 32-bit binary value.

Sixth stage

After applying substitution Tables or S-boxes on Bis, another permutation is performed on the result.

Permutation $\mathrm{P}$

1672021

29122817

1152326

5183110

282414

322739

1913306

2211425

Briefly, $\mathrm{f}$ function is computed as:

$\mathrm{f}=\mathrm{P}(\mathrm{S}[1](\mathrm{B}[1]) \ldots \mathrm{S}[8](\mathrm{B}[8]))$

For example:

S1(B1)S2(B2)S3(B3)S4(B4)S5(B5)S6(B6)S7(B7)S8(B8)

$=01011100100000101011$

010110010111

$\mathrm{f}=00100011010010101010100110111011$

Then,

$\mathrm{R}[1]=\mathrm{L}[0]$ XOR f(R[0], K[1] )

$=11001100000000001100110011111111$

XOR 00100011010010101010100110111011 
$=11101111010010100110010101000100$

L1 was computed already:

$\mathrm{L}[1]=\mathrm{R}[0]=11110000101010101111000010101010$

Here, one round of 16 rounds of algorithm is finished.

Start of second round:

According to the general formula we have:

$\mathrm{L}[2]=\mathrm{R}[1]$

$\mathrm{R}[2]=\mathrm{L}[1]+\mathrm{f}(\mathrm{R}[1], \mathrm{K}[2])$

Its computation is simple and this trend is continued to the end of 16 rounds.

At the end of round 16, the result is L16, R16. Here, these two blocks are changed, it means that

$\mathrm{R}$ [16] L [16]

And the final permutation is performed on it as following Table:

$\mathrm{IP}^{\wedge}-1$

408481656246432

397471555236331

386461454226230

375451353216129

364441252206028

353431151195927

\subsection{Simulated Code of DES Algorithm in MATLAB}

Clear

tic

$\mathrm{M}=$ 'AF88888888555456;'

$\mathrm{K}=$ '1256984563214569;'

$\mathrm{MB} ;[]=$

for $\mathrm{i}=1 ; 16$

$\mathrm{Mi}=\mathrm{M}(\mathrm{I} ;($

$\mathrm{MBi}=\left[{ }^{\circ} 0000\right.$ ',, $\operatorname{dec} 2 \mathrm{bin}(\mathrm{hex} 2 \operatorname{dec}(\mathrm{Mi} ;[(($

$\mathrm{MBi}=\mathrm{MBi}($ end-3; end;

$\mathrm{MBi}=[\operatorname{str} 2$ num $(\mathrm{MBi}(1))$, str2num( $(\mathrm{MBi}(2)), \operatorname{str} 2$ num(MBi(3)),str2num(MBi(4; $](($

$\mathrm{MB}=[\mathrm{MB}, \mathrm{MBi} ;[$

end

$\mathrm{M}=\mathrm{MB}$;

$\mathrm{KB} ;[]=$

for $\mathrm{i}=1 ; 16$

$\mathrm{Ki}=\mathrm{K}(\mathrm{i} ;($

$\mathrm{KBi}=[' 0000$ ',dec2bin(hex $2 \operatorname{dec}(\mathrm{Ki} ;[(($

$\mathrm{KBi}=\mathrm{KBi}$ (end-3; end;

$\mathrm{KBi}=[\operatorname{str} 2$ num $(\mathrm{KBi}(1), \operatorname{str} 2$ num $(\mathrm{KBi}(2)), \operatorname{str} 2$ num $(\mathrm{KBI}(3)), \operatorname{str} 2$ num $(\mathrm{KBi}(4 ;[(($

$\mathrm{KB}=[\mathrm{KB}, \mathrm{KBi}$;

end

$\mathrm{K}=\mathrm{KB}$;

$\mathrm{E}=[32,1,2,3,4,5$;

$9,8,7,6,5,4$

$9,10,11,12,13,8$

$12,13,14,15,16,17$

$16,17,18,19,20,21$;

$20,21,22,23,24,25$;

$24,25,26,27,28,29$;

$28,29,30,31,32,1$;

$\mathrm{S} 1=14,4,13,1,2,15,11,8,3,10,6,12,5,9,0,7$;

$8,3,5,9,11,12,6,10,1,13,2,14,4,7,15,0$;

$0,5,10,3,7,9,12,15,11,2,6,13,8,14,1,4$;

$13,6,0,10,14,3,11,5,7,1,9,4,2,8,12,15$;

$\mathrm{S} 2=15,1,8,14,6,11,3,4,9,7,2,13,12,0,5,10$;

$5,11,9,6,10,1,0,12,14,8,2,15,7,4,13,3$;

\author{
342421050185826 \\ 33141949175725 \\ For example, based on the selected values we have: \\ L16 = 01000011010000100011001000110100 \\ $\mathrm{R} 16=00001010010011001101100110010101$ \\ $\mathrm{R}[16] \mathrm{L}[16]=00001010010011001101100110010101$ \\ 010000110100001000110010 \\ 00110100 \\ $\mathrm{IP}^{\wedge}-1=10000101 \quad 11101000 \quad 0001001101010100$ \\ 000011110000101010110100 \\ 00000101 (bin) \\ $=85 \mathrm{E} 813540 \mathrm{~F} 0 \mathrm{AB} 405$ (hex) \\ Or briefly: \\ $\mathrm{M}=0123456789 \mathrm{ABCDEF}$ \\ The applied key for coding: \\ Key $=13345779$ 9B BC DF F1 \\ Encoded output \\ $\mathrm{C}=85 \mathrm{E} 813540 \mathrm{~F} 0 \mathrm{AB} 405$
}


$15,2,3,9,6,12,8,5,1,13,4,10,117,14,0$

$9,14,5,0,12,7,6,11,2,4,15,3,1,10,8,13$;

$\mathrm{S} 3=10,0,9,14,6,3,15,5,1,13,12,7,11,4,2,8$;

$\mathrm{P}=[16,7,20,21,29,12,28,17,1,15,23,26,5,18,31,10,2,8,24,14,32,27,3,9,19,13,30,6,22,11,4,25 ;[$

$\mathrm{PC} 1=[57,49,41,33,25,17,9,1,58,50,42,34,26,18,10,2,59,51,43,35,27,19,11,3,60,52,44$,

$36,63,55,47,39,31,23,15,7,62,54,46,38,30,22,14,6,61,53,45,37,29,21,13,5,28,20,12,4 ;[$

PC2 $=[14,17,11,24,1,5,3,28,15,6,21,10,23,19,12,4,26,8,16,7,27,20,13,2,41,52,31,37,4$

$7,55,30,40,51,45,33,48,44,49,39,56,34,53,46,42,50,36,29,32 ;[$

$\mathrm{Ki}=\mathrm{zeros}(16,48 ;($

$\mathrm{K} \_\mathrm{PC} 1=\mathrm{K}(\mathrm{PC} 1$

$\mathrm{CO}=\mathrm{K} \_\mathrm{PC} 1(1 ; 28 ;($

DOK_PC1 $129 ; 56 ;($

for $\mathrm{i}=1 ; 16$

if $\mathrm{i}==1|| \mathrm{i}==2|| \mathrm{i}==9|| \mathrm{I}==16$

$1,15,11,12,14,5,8,2,10,6,4,3,9,0,7,13$; $7,14,10,5,12,2,1,11,0,3,15,8,9,4,6,13$; $12,2,5,11,3,14,15,47,8,9,6,0,13,10,1$; $\mathrm{S} 4=7,13,14,3,0,6,9,10,1,2,8,5,11,12,4,15$; 9, 14, 10, 1 12, 2, 7, 4, 3, 0, 15, 6, 5, 11, 8, 13; $4,8,2,5,14,3,1,15,137,11,12,0,9,6,10$; $14,2,7,12,11,5,4,9,8,13,1,10,6,0,15,3$; $\mathrm{S} 5=2,12,4,1,7,10,11,6,8,5,3,15,13,0,14,9$; $6,8,9,3,10,15,0,5,1,13,7,4,12,2,11,14$; $14,0,3,6,5,12,9,15,8,7,13,10,11,1,2,4$; $3,5,4,10,9,0,15,6,13,2,14,1,7,12,8,11$; $\mathrm{S} 6=12,1,10,15,9,2,6,8,0,13,3,4,14,7,5,11$; $8,3,11,0,14,13,1,6,5,9,12,7,2,4,15,10$; $6,11,13,1,10,4,0,7,3,12,8,2,5,15,14,9$; $13,8,0,6,7,1,14,11,10,15,5,9,12,2,3,4$; $\mathrm{S} 7=4,11,2,14,15,0,8,13,3,12,9,7,5,10,6,1$; $6,8,15,2,12,5,3,14,10,1,9,4,7,11,0,13$; $2,9,5,0,8,6,15,10,14,7,3,12,13,11,4,1$; $12,3,2,14,15,0,5,9,7,10,4,1,8,13,11,6$; $\mathrm{S} 8=13,2,8,4,6,15,11,1,10,9,3,14,5,0,12,7$; $2,9,14,0,11,6,5,12,4,7,3,10,8,13,15,1$; $8,5,3,15,13,10,6,0,2,14,12,9,1,4,11,7$; $11,6,5,3,0,9,12,15,13,8,10,4,7,14,1,2$; $\mathrm{P}=[16,7,20,21,29,12,28,17,1,15,23,26,5,18,31,10,2,8,24,14,32,27,3,9,19,13,30,6,22,11,4,25 ;[$

$\mathrm{PC} 1=[57,49,41,33,25,17,9,1,58,50,42,34,26,18,10,2,59,51,43,35,27,19,11,3,60,52,44$, $36,63,55,47,39,31,23,15,7,62,54,46,38,30,22,14,6,61,53,45,37,29,21,13,5,28,20,12,4 ;[$ 
PC2 $=[14,17,11,24,1,5,3,28,15,6,21,10,23,19,12,4,26,8,16,7,27,20,13,2,41,52,31,37,4$

$7,55,30,40,51,45,33,48,44,49,39,56,34,53,46,42,50,36,29,32 ;[$

$\mathrm{Ki}=\operatorname{zeros}(16,48 ;($

K_PC $1=\mathrm{K}(\mathrm{PC} 1$

$\mathrm{CO}=\mathrm{K} \_\mathrm{PC} 1(1 ; 28 ;($

$\mathrm{DO}=\mathrm{K} \_\mathrm{PC} 1(29 ; 56 ;($

for $i=1 ; 16$

if $\mathrm{i}==1|| \mathrm{i}==2|| \mathrm{i}==9|| \mathrm{I}==16$

$1,15,11,12,14,5,8,2,10,6,4,3,9,0,7$;

$7,14,10,5,12,2,1,11,0,3,15,8,9,4,6,13$;

$12,2,5,11,3,14,15,4,7,8,9,6,0,13,10,1$;

$\mathrm{S} 4=7,13,14,3,0,6,9,10,1,2,8,5,11,12,4,15$;

$9,14,10,1,12,2,7,4,3,0,15,6,5,11,8,13$;

$4,8,2,5,14,3,1,15,13,7,11,12,0,9,6,10$; $14,2,7,12,11,5,4,9,8,13,1,10,6,0,15,3$; $\mathrm{S} 5=2,13,4,1,7,10,11,6,8,5,3,15,13,0,14,9$; $6,8,9,3,10,15,0,5,1,13,7,4,13,2,11,14$; $14,0,3,6,5,12,9,15,8,7,13,10,11,1,2,4$; $3,5,4,10,9,0,15,6,13,2,14,1,7,12,8,11$; $\mathrm{S} 6=12,1,10,15,9,2,6,8,0,13,3,4,14,7,5,11$; $8,3,11,0,14,13,1,6,5,9,12,7,2,4,15,10$; $6,11,13,1,10,4,0,7,3,12,8,2,5,15,14,9$; $13,8,0,6,7,1,14,11,10,15,5,9,12,2,3,4$; $\mathrm{S} 7=4,11,2,14,15,0,8,13,3,12,9,7,5,10,6,1$; $6,8,15,2,12,5,3,14,10,1,9,4,7,11,0,13$; $2,9,5,0,8,6,15,10,14,7,3,12,13,11,4,1$; $12,3,2,14,15,0,5,9,7,10,4,1,8,13,11,6$; $\mathrm{S} 8=13,2,8,4,6,15,11,1,10,9,3,14,5,0,12,7$; $2,9,14,0,11,6,5,12,4,7,3,10,8,13,15,1$; $8,5,3,15,13,10,6,0,2,14,12,9,1,4,11,7$; $11,6,5,3,0,9,12,15,13,8,10,4,7,14,1,2$; 
$\mathrm{D} 0=[\mathrm{D} 0(2 ;$ end $), \mathrm{D} 0(1$

else

$\mathrm{CO}=[\mathrm{CO}(3 ;$ end $), \mathrm{CO}(1.2 ;[($

$\mathrm{D} 0=[\mathrm{DO}(3 ; \mathrm{end}), \mathrm{DO}(1.2 ;[($

end

K_LS $=[\mathrm{CO}, \mathrm{D} 0 ;($

$\mathrm{Ki}(\mathrm{i}, ;)=\mathrm{K} \_$LS $(\mathrm{PC} 2 ;($

end

$\mathrm{L}=\mathrm{M}(1 ; 32 ;($

$\mathrm{R}=\mathrm{M}(33 ; 64 ;($

for $i=1 ; 16$

$\mathrm{E} 0=$ reshape $\left(\mathrm{E}^{\prime}, 1,48 ;(\right.$

$R \_E=R(E O$

R_Ki=mod(R_E+Ki(i,;),2;(

$\mathrm{B}=\mathrm{R} \_\mathrm{Ki}(1 ; 6 ;($

$\mathrm{x}=\mathrm{B}(1) * 2+\mathrm{B}(6)+1$

$\mathrm{y}=\mathrm{B}(2) * 8+\mathrm{B}(3) * 4+\mathrm{B}(4) * 2+\mathrm{B}(5)+1$

$\mathrm{C}=\left[{ }^{\prime} 00000^{\prime}, \operatorname{aec} 2 \mathrm{bin}(\mathrm{S} 1\right.$ (x,y [((

$\mathrm{C}=\mathrm{C}$ (end-3; end ;

$\mathrm{C} 1=[\operatorname{str} 2$ num $(C(1)), \operatorname{str} 2$ num $(C(2)), \operatorname{str} 2$ num $(C(3)), \operatorname{str} 2 \operatorname{num}(\mathrm{C}(4 ;(([$

$\mathrm{B}=\mathrm{R} \_\mathrm{Ki}(7 ; 12 ;($

$\mathrm{x}=\mathrm{B}(1) * 2+\mathrm{B}(6)+1$;

$\mathrm{y}=\mathrm{B}(2) * 8+\mathrm{B}(3) * 4+\mathrm{B}(4) * 2+\mathrm{B}(5)+1$;

$\mathrm{C}=\left[{ }^{\prime} 0000\right.$ ', aec2bin(S2) $\mathrm{x}, \mathrm{y}[(($

$\mathrm{C}=\mathrm{C}$ (end- 3 ; end ;

$\mathrm{C} 2=[\operatorname{str} 2 \operatorname{num}(C(1)), \operatorname{str} 2 \operatorname{num}(C(2)), \operatorname{str} 2 \operatorname{num}(C(3)), \operatorname{str} 2 \operatorname{num}(C(4) ;([$

$\mathrm{B}=\mathrm{R} \_\mathrm{Ki}(13 ; 18 ;($

$\mathrm{x}=\mathrm{B}(1) * 2+\mathrm{B}(6)+1$;

$\mathrm{y}=\mathrm{B}(2) * 8+\mathrm{B}(3) * 4+\mathrm{B}(4) * 2+\mathrm{B}(5)+1 ;$

$\mathrm{C}=[\mathrm{\prime} 0000$ ', dec2bin(S3) x,y [((

$\mathrm{C}=\mathrm{C}$ (end-3; end ( 
$\mathrm{C} 3=[\operatorname{str} 2 \operatorname{num}(C(1)), \operatorname{str} 2 \operatorname{num}(C(2)), \operatorname{str} 2 \operatorname{num}(C(3)), \operatorname{str} 2 \operatorname{num}(C(4 ;(([$

$\mathrm{B}=\mathrm{R} \_$Ki $(19 ; 24 ;($

$\mathrm{x}=\mathrm{B}(1) * 2+\mathrm{B}(6)+1 ;$

$\mathrm{y}=\mathrm{B}(2) * 8+\mathrm{B}(3) * 4+\mathrm{B}(4) * 2+\mathrm{B}(5)+1 ;$

$\mathrm{C}=[' 0000 ", \operatorname{dec} 2 \operatorname{bin}(\mathrm{S} 4(\mathrm{x}, \mathrm{y}[(($

$\mathrm{C}=\mathrm{C}$ (end- 3 ; end ;

$\mathrm{C} 4=[\operatorname{str} 2 \operatorname{num}(\mathrm{C}(1)), \operatorname{str} 2 \mathrm{num}(\mathrm{C}(2)), \operatorname{str} 2 \mathrm{num}(\mathrm{C}(3)), \operatorname{str} 2 \operatorname{num}(\mathrm{C}(4 ;(([$

$\mathrm{B}=\mathrm{R} \_\operatorname{Ki}(25 ; 30 ;($

$\mathrm{x}=\mathrm{B}(1) * 2+\mathrm{B}(6)+1$;

$\mathrm{y}=\mathrm{B}(2) * 8+\mathrm{B}(3) * 4+\mathrm{B}(4) * 2+\mathrm{B}(5)+1$;

$\mathrm{C}=\left[{ }^{\prime} 0000 ", \operatorname{dec} 2 \mathrm{bin}(\mathrm{S} 5\right.$ (x,y [((

$\mathrm{C}=\mathrm{C}(\mathrm{end}-3$; end ;

$\mathrm{C} 5=[\operatorname{str} 2 \mathrm{num}(\mathrm{C}(1)), \operatorname{str} 2 \mathrm{num}(\mathrm{C}(2)), \operatorname{str} 2 \mathrm{num}(\mathrm{C}(3)), \operatorname{str} 2 \mathrm{num}(\mathrm{C}(4 ;[(($

$\mathrm{B}=\mathrm{R} \_$Ki $(31 ; 36$ (

$\mathrm{x}=\mathrm{B}(1) * 2+\mathrm{B}(6)+1$;

$\mathrm{y}=\mathrm{B}(2) * 8+\mathrm{B}(3) * 4+\mathrm{B}(4) * 2+\mathrm{B}(5)+1$;

$\mathrm{C}=\left[{ }^{\prime} 0000\right.$ ', dec2bin $(\mathrm{S} 6(\mathrm{x}, \mathrm{y}[(($

$\mathrm{C}=\mathrm{C}$ (end-3;end ;

C6 $=[\operatorname{str} 2$ num $(C(1)), \operatorname{str} 2$ num $(C(2)), \operatorname{str} 2$ num $(C(3)), \operatorname{str} 2 \operatorname{num}(C(4 ;[(($

$\mathrm{B}=\mathrm{R} \_$Ki $(37 ; 42 ;($

$\mathrm{x}=\mathrm{B}(1) * 2+\mathrm{B}(6)+1$;

$\mathrm{y}=\mathrm{B}(2) * 8+\mathrm{B}(3) * 4+\mathrm{B}(4) * 2+\mathrm{B}(5)+1$

$\mathrm{C}=\left[{ }^{\prime} 0000 ", \operatorname{dec} 2 \operatorname{bin}(\mathrm{S} 7(\mathrm{x}, \mathrm{y}[((\right.$

$\mathrm{C}=\mathrm{C}($ end-3; end $(\mathrm{C} 7=[\operatorname{str} 2 \mathrm{num}(\mathrm{C}(1)), \operatorname{str} 2 \mathrm{num}(\mathrm{C}(2)), \operatorname{str} 2$ num $(C(3)), \operatorname{str} 2 \operatorname{num}(\mathrm{C}(4 ;[[($

$\mathrm{B}=\mathrm{R} \_\mathrm{Ki}(43 ; 48 ;($

$\mathrm{x}=\mathrm{B}(1) * 2+\mathrm{B}(6)+1 ;$

$\mathrm{y}=\mathrm{B}(2) * 8+\mathrm{B}(3) * 4+\mathrm{B}(4) * 2+\mathrm{B}(5)+1$;

$\mathrm{C}=\left[{ }^{\prime} 0000\right.$ ', aec $2 \mathrm{bin}(\mathrm{S} 8(\mathrm{x}, \mathrm{y} ;[((\mathrm{C}$

$\mathrm{C}=\mathrm{C}($ end-3; end $(\mathrm{C} 8=[\operatorname{str} 2$ num $(\mathrm{C}(1)), \operatorname{str} 2$ num $(\mathrm{C}(2)), \operatorname{str} 2$ num $(\mathrm{C}(3)), \operatorname{str} 2$ num $(\mathrm{C}(4 ;[[($

$\mathrm{C}=[\mathrm{C} 1, \mathrm{C} 2, \mathrm{C} 3, \mathrm{C} 4, \mathrm{C} 5, \mathrm{C} 6, \mathrm{C} 7, \mathrm{C} 8 ;[$ 


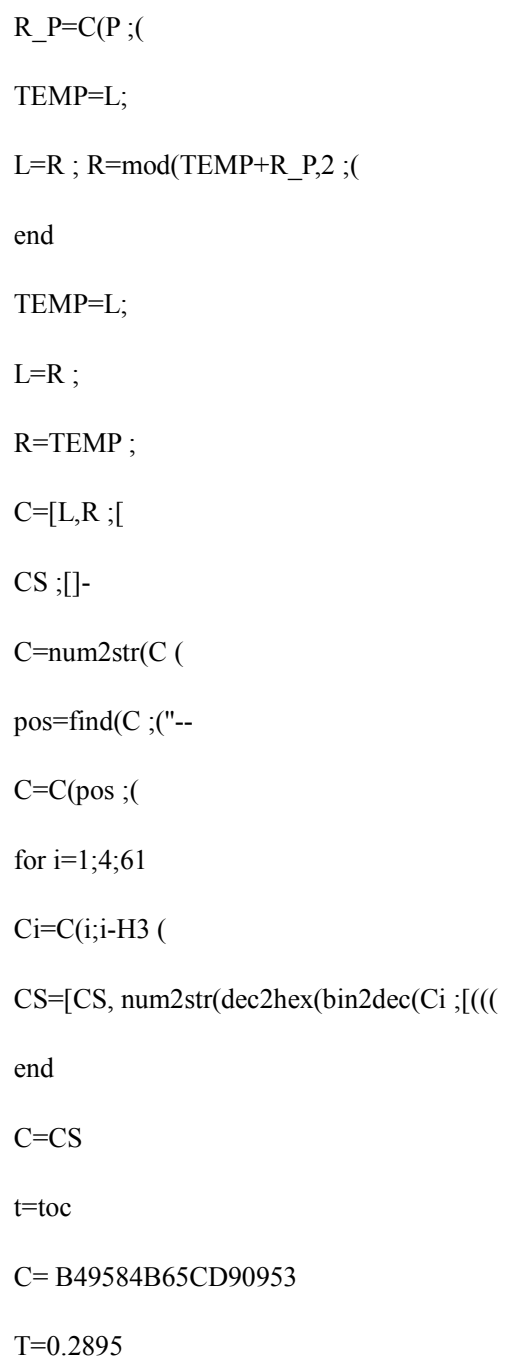

\subsection{Implementation of DES Algorithm in C++ Application}

\#include;stdio.h>

\#include;fstream.h>

\#include;string.h>

\#include;conio.h>

\#include;iostream.h>

int $\operatorname{key}(64]=\{$

$0,0,0,1,0,0,1,1$,

$0,0,1,1,0,1,0,0$

$0,1,0,1,0,1,1,1$

$0,1,1,1,1,0,0,1$,

$1,0,0,1,1,0,1,1$,

$1,0,1,1,1,1,0,0$,

$1,1,0,1,1,1,1,1$

$1,1,1,1,0,0,0,1$

class Des

\}

public;

int 
keyi[16][48), total[64), left|32), right|32), ck[28), dk[28), expansion[48),z[48),xor1[48), sub[32],p[32],xor2[32],temp[64], pc1[56],ip[64],inv[8][8];

char final[1000];

void IP();

void PermChoice1();

void PermChoice2();

void Expansion();

void inverse();

void xor two();

void xor oneE(int);

void xor oneD(int);

void substitution();

void permutation();

void keygen();

char* Encrypt(char *);

char * Decrypt $(\operatorname{char} *)$;

;

void Des;;IP()

\{

int $\mathrm{k}=58$, ;

for $(\mathrm{i}=0 ; \mathrm{i}<32 ; \mathrm{i}++)$

\{

$\mathrm{ip}[\mathrm{i}]=\operatorname{total}[\mathrm{k}-1]$;

if $(\mathrm{k}-8>0) \mathrm{k}=\mathrm{k}-8$;

else $\mathrm{k}=\mathrm{k}+58$;

\}

$\mathrm{k}=57$;

for $(\mathrm{i}-32 ; \mathrm{i}<64 ; \mathrm{i}++)$

\{

ipsi] $=$ total[k-1];

if $(\mathrm{k}-8>0) \mathrm{k}=\mathrm{k}-8$;

else $\quad \mathrm{k}=\mathrm{k}+58$;

\}

void Des;;PermChoice1()

\{

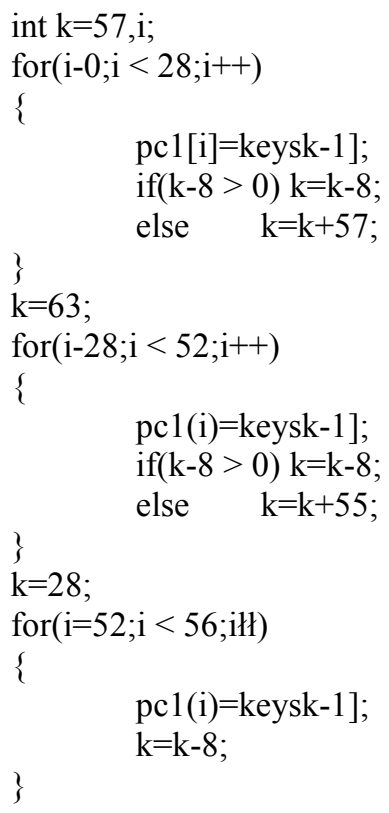




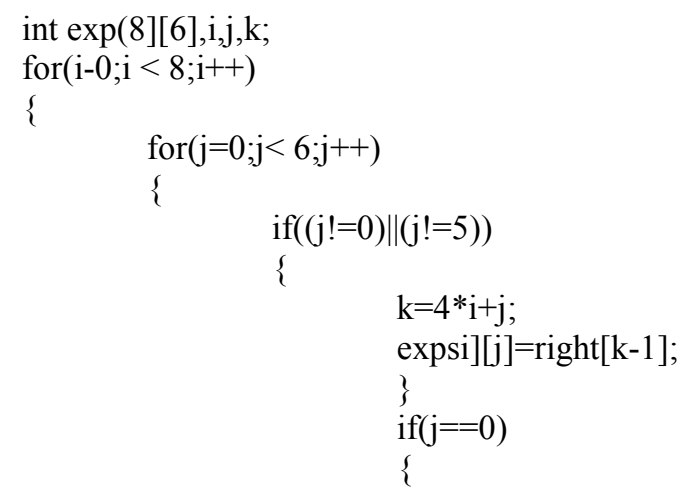

substitution();

permutation();

xor two();

for $(\mathrm{i}-0 ; \mathrm{i}<32 ; \mathrm{i}++)$ left $[\mathrm{i}]=\operatorname{right}[\mathrm{i}]$;

for $(\mathrm{i}-0 ; \mathrm{i}<32 ; \mathrm{i}++) \operatorname{right}[\mathrm{i}]=$ xor $2 \mid[\mathrm{i}]$;

\}

for $(\mathrm{i}-0 ; \mathrm{i}<32 ; \mathrm{i}++)$ tempsi] $=$ right $[\mathrm{i}]$;

for $(; i<64 ; i++)$ tempsi] $=$ left $[i-32]$;

inverse();

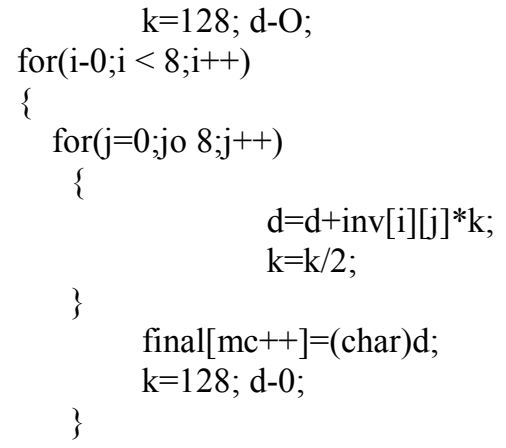

\}

final $[\mathrm{mc}]=' \backslash 0$ ';

return(final);

\}

char * Des;;Decrypt(char *Text!)

\{

int $\mathrm{i}, \mathrm{a} 1, \mathrm{j}, \mathrm{nB}, \mathrm{m}, \mathrm{iB}, \mathrm{k}, \mathrm{K}, \mathrm{BI} 8], \mathrm{n}, \mathrm{t}, \mathrm{d}$, round,

char ${ }^{*}$ Text=new char(1000];

unsigned char ch;

strcpy(Text,Text1);

$\mathrm{i}=\operatorname{strlen}(\mathrm{Text})$;

keygen();

int mo-O;

for $(\mathrm{iB}=0, \mathrm{nB}=0, \mathrm{~m}=0 ; \mathrm{m} \ll(\operatorname{strlen}($ Text $) / 8) ; \mathrm{m} \mathrm{\# 4})$

\{

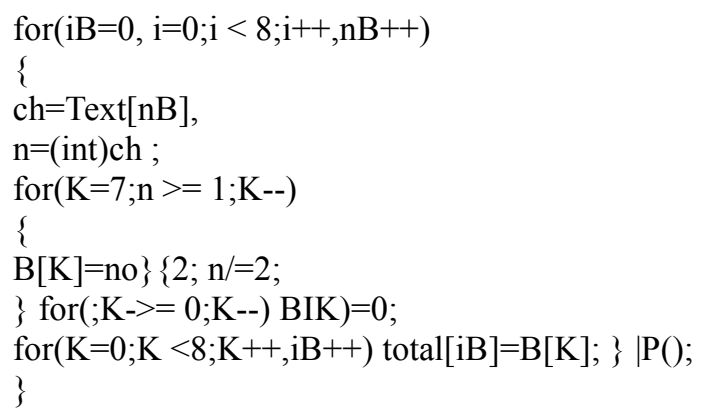

IP();

for $(\mathrm{i}-0 ; \mathrm{i}<32 ; \mathrm{i}++) \operatorname{left}[\mathrm{i}]=\operatorname{total}[\mathrm{i}]$; 


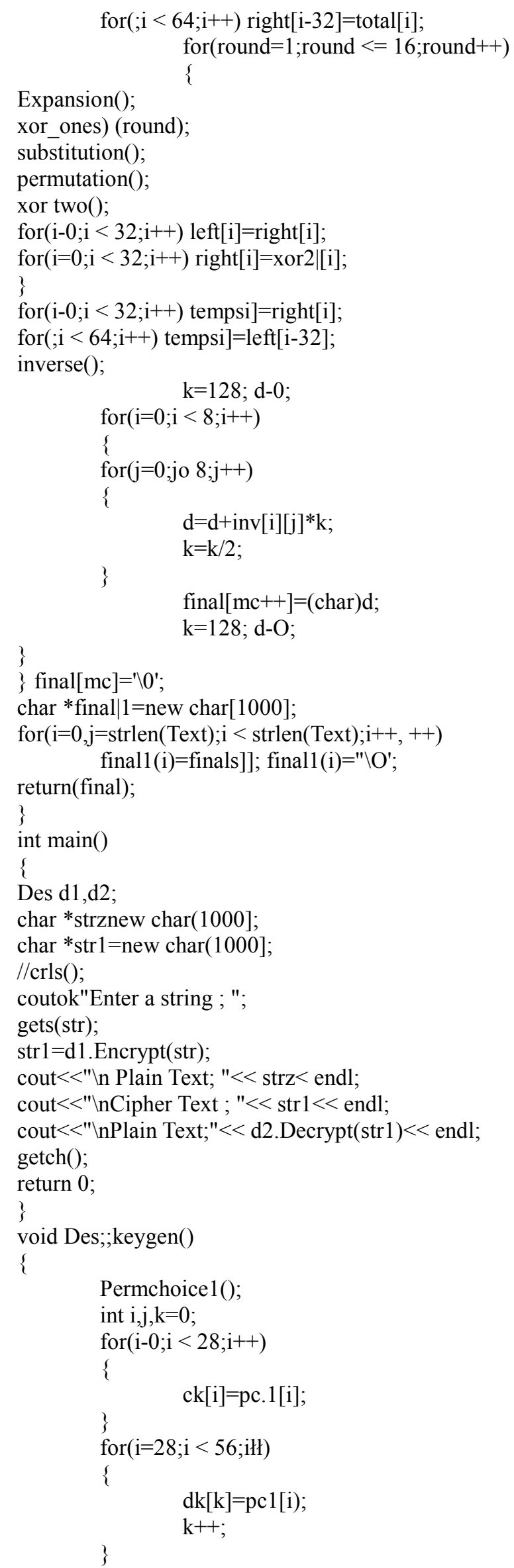




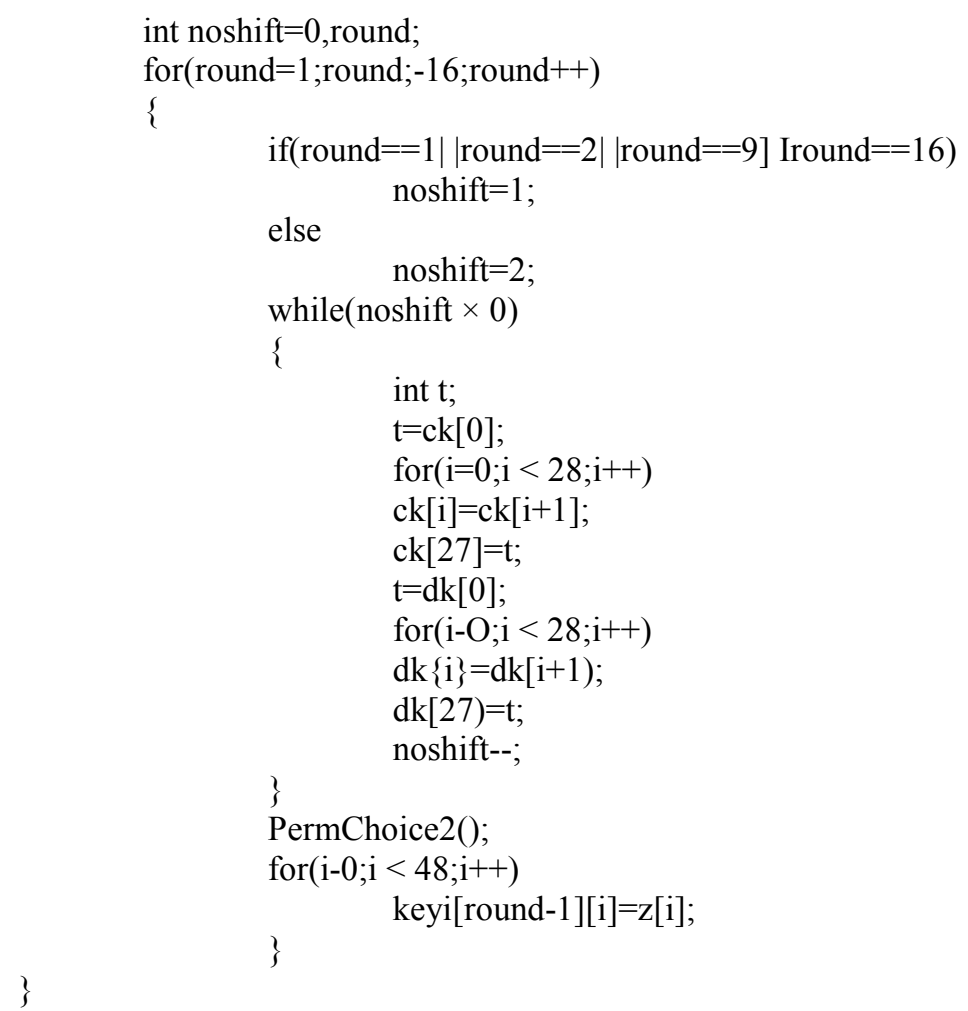

Enter a string ; arash

Plain Text ; arash

cipher Text; ÓÓ\|

\section{Conclusion}

DES algorithm is one of the most important and common cryptography algorithms as applied in security of many applications as financial transaction, data transfer, smart cards, etc. In software implementation of this algorithm, it is always considered by researchers and experts in this field. Despite the significance of this issue, it is not considered mostly in our country. In this thesis, besides recognition of the function of this algorithm and simulation of algorithm performance in MATLAB, an efficient implementation by $\mathrm{C}$ language is performed. One of the results of this thesis is providing security of various systems as sending and receiving important data without classification. Also, smart cards or various security transactions can be used. The results also can be used to implement secure and recognize algorithm of 3-DES.

\section{References}

[1] B. Schneir, Applied cryptography, John Wiley, 1996.

[2] A. Saloma, Public key cryptography, 1990.

[3] G. Brassard,"Modern cryptography, a tutorial”, 1988.
[4] C. G. Shannon,"Communication theory in security systems", Bell Sys. Tech. Journal, Vol.28, Oct. 1949.

[5] W. Diffie and M. Hellman,"New directions in cryptography", IEEE trans. On IT, Vol. 22, Nov. 1976.

[6] W. Diffie and M. Hellman,"Privacy and Authentication: An introduction to cryptography, New directions in cryptography", IEEE trans, Vol. 67, 1979.

[7] J.L. Massey, "An Introduction to contemporary cryptography", IEEE Proc, Vol.76, May 1983.

[8] Chan, M.H.L and Donaldson, R.W. "Amplitude, width and interarrival distributions for noise impulses on intrabuilding power line communication networks", IEEE Trans. Electromagn. Compat. Vol. EMC-31, pp320-323, Aug 1989.

[9] Canete, F. Cort'es, J. D'iez, L and Entrambasaguas, J. “A channel model proposal for indoor power line communications," in IEEE Communications Magazine, January 2011.

[10] Marihart, D. J. "Communications Technology Guidelines for EMS/SCADA Systems" IEEE TRANS. ON POW.DELIVERY, VOL. 16, NO. 2, APRIL 2001.

[11] Dostert, K "Telecommunications over the Power Distribution Grid- Possibilities and Limitations", Proc 1997 Internat.Symp.on Power Line Comms and its Applications pp1-9, 1997. 